\title{
VARIAÇÃO LINGÜÍSTICA E ENSINO DE LÍNGUA PORTUGUESA
}

\author{
José Luiz da Veiga Mercer * \\ Maria José Foltran *
}

\section{A}

constatação do fracasso do ensino de português já deixou de ser tema apenas de educadores e lingüistas para tornar-se um lugarinicio de ano a imprensa se ocupa de renovar o registro da falência com matéria relativa à prova de redação dos exames vestibulares, em que a miséria do português apresentado pelos candidatos é fartamente exemplificada com um sem-número de crros risíveis, de ortografia, de língua ou de construção.

Uma das causas imediatas desse malogro - e certamente a principal delas - deve buscar-se na tentativa de democratização do acesso à escola. que se iniciou ainda na ditadura de Getúlio Vargas, nos anos 40 , sendo ministro Gustavo Capanema, e que veio tomar notável impulso na década de 70, sob a égide do assim chamado "Milagre Brasileiro". 0 projeto de universalização do ensino se traduziu por uma verdadeira explosão da rede escolar, que foi expandida de forma tāo ampla quanto rápida. Assim se possibilitou o acesso aos bancos escolares de uma nova clientela, que fala variedades de língua portuguesa que não aquela utilizada pelo sistema

* Universidade Federal do Paraná 
escolar, vale dizer, pelos professores, educadores e materiais didáticos. Instalou-se na escola, por conseguinte, conflito lingüistico para o qual a instituição se encontrava tão despreparada que sequer se deu conta, realmente, da extensão do problema. A escola simplesmente ignorou o conflito.

Atribuir o fracasso do portuguès à tentativa de universalização do ensino não significa condenar a política da democratização da escola. Importa simplesmente admitir que nem tudo correu bem. Os percalços na implementação dessa política são evidentes. A expansāo física da rede escolar, isto é, da construção de novos edifícios escolares podia fazer-se a um ritmo que a formação de professores não podia acompanhar. Uma das conseqüências mais conhecidas - e graves - desse descompasso foi a improvisaçāo de professores: profissionais nāo habilitados ao magistério assumiram um lugar na sala de aula. Nas pequenas cidades do interior, que sequer dispunham de suficiente pessoal de nivel universitário, a improvisação se fez de forma ainda mais grosseira. Quando ficou evidente a necessidade de formação específica de professores, iniciou-se um programa de aperfeiçoamento desses professores leigos, ao qual é de justiça creditar um bom resultado nos limites das circunstâncias. A longo prazo, porém, seria necessário esperar pelos profissionais egressos das faculdades de filosofia que foram sendo criadas um tanto às pressas. Aliás, essas escolas de magistério também foram marcadas pela improvisação, engendrando, assim, um círculo vicioso de formação precária.

0 processo de expansão da rede escolar se fez, pois, privilegiando a quantidade em detrimento da qualidade, a base física $\mathrm{e}$ não $\alpha$ recursos humanos. Não bastasse isso, quando o quadro de magistério atingiu certa ordem de grandeza, a sua ampliação continuou financeiramente possível apenas pelo aviltamento da remuneraçāo. A perda do reconhecimento prolissional implicada pelos baixos salärios importou em perda de prestigio social do magistério, que deixou, com isso, de atrair os melhores alunos e foi rebaixado a op̧ão dos menos competentes, em via de regra. A esse quadro veio somar-se a crise financeira da Administração Pública e, por ai, da economia nacional, que veio tornar ainda mais agudos os problemas da escola pública.

A rigor, não é o ensino de portugués que vai mal. E' todo o sistema escolar que entrou em colapso. 0 que se poderia dizer é que, entre todas as disciplinas, a de Portugués parece ter o mérito de ir particularmente mal. E o que particularize a situação da disciplina de Portugués é justamente o referido conflito de variedades lingüisticas, que se tomou crítico com a 
admissão de um novo alunado, oriundo das classes sociais mais baixas e/ou do meio rural. Conflito que consta da escola ter uma língua e seus alunos outra, fato que não tem análogo em outras disciplinas: as crianças não cheqam à escola com uma Aritmética diferente da praticada pela instituição, nem a História do Brasil é matéria de divergência. Mas a língua é.

\section{A LÍNGUA E SUAS VARIEDADES}

O dissenso lingüistico vem da noção falsa de que a língua portuguesa só comporta uma forma válida. A escola apresenta a lingua - aliás, a sua lingua - como um fato único e homogêneo e tudo o que se afasta desse padrão é considerado errado, é visto como um desvio de uma norma pronta, única, acabada. Um nome como língua portuguesa ou lingua inglesa, como se sabe, nāo é senão uma cômoda etiqueta com que se designa um conjunto de variedades que se distribuem segundo as classes sociais as situações de uso e segundo a regiāo geográfica. E se nos colocarmos na perspectiva histórica, ainda temos que admitir que com "Língua portuguesa" ficam abrigadas todas as variedades utilizadas ao longo desses séculos de uma mesma tradição linguiística.

Não precisamos ir muito longe para comprovarmos o fato de que a língua é um conjunto heterogêneo de variedades. Para isso, basta observarmos a nossa própria maneira de falar, ou seja, a forma como variamos a nossa escolha vocabular, as estruturas sintáticas e a mancira de pronunciarmos determinadas palavras em função de uma determinada situação. Com certeza, todos poderão perceber que a forma que utilizamos para a nossa comunicação é de um jeito se estamos conversando com familiares ou pessoas mais íntimas, é de outro jeito se estamos falando com quem temos um relacionamento mais distante. $\mathrm{Na}$ verdade, essa fala será altamente influenciada pela situação que estamos vivendo e pelo nosso interlocutor, isto $\mathfrak{c}$, pela pessoa ou pessoas com quem estamos conversando. As características desse interlocutor são decisivas na medida em que alteramos a nossa forma de expressão de acordo com o grau de intimidade que temos com ele, com a formação ou escolaridade que ele tem, com a posição que ele exerce na organização social de que participamos.

Esse é na realidade, apenas um dos eixos que orientam a variação lingüistica: a variação tendo $\mathrm{em}$ vista o mesmo falante ou variação estilistica. Se nos aprofundarmos um pouco mais na questão, constatamos 
que a língua varia também determinada por outros fatores como o tempo, 0 espaço, a estratificação social.

Para comprovarmos que a lingua varia no tempo, é suficiente compararmos textos contemporâneos com textos de uma época anterior qualquer. Quanto mais afastada for essa época, encontraremos um número maior de exemplos de mudanças. 0 que aconteceu? A língua portuguesa foi deturpando-se de uma geração para outra ou foi aperfeiçoando-se? Nem uma coisa nem outra. Por isso é desaconselhável dizer que a língua evolui. Utilizando esse termo, fica a impressão de que ela foi se corrigindo, cla foi melhorando com o decorter do tempo e essa é uma conclusão falsa. A língua portuguesa utilizada nos séculos anteriores era ideal para as necessidades dos seus falantes. Da mesma forma, a lingua portuguesa que utilizamos hoje preenche todos os requisitos de que precisamos. Cientificamente, portanto, a única afirmação que pode ser feita em relação a esse fato é que a lingua muda. simplesmente.

Quanto ao espaço, também é fácil perceber que a língua falada nas diferentes regiōes não é a mesma. Variam, de região para região, a forma de pronunciarmos as palavras, o vocabulário e, inclusive, a forma que utilizamos para estruturar algumas oraçōes. Realizaçōes como menimu. mininu ou méninu são exemplos das diferentes pronúncias que a palavra menino pode receber. Mandioca, aipim, macareira comprovam uma escolha vocabular diferente e ele está a cantar e ele está cantando são estruturas que demonstram op̧̧ões sintáticas diferentes que mudam de lugar para lugar.

0 que vimos anteriormente não é ainda suficiente para esgotar toda a questão de variação lingüistica. Se tomarmos, por exemplo, um tempo determinado (a década em que vivemos) e um espaço determinado (a regiāo onde moramos), será que todos os falantes envolvidos nesse tempo e nesse espaço falam da mesma maneira? Qualquer um responderia prontamente que não. Isso se deve ao fato de que a sociedade está dividida em grupos cujas diferenças são condicionadas por fatores como classe social, educação, profissão, sexo, idade. Cada grupo se caracteriza por experiencias sociais diversas e essas diferenças vão refletir-se na forma de cada um deles se expressar.

Assim, podemos encontrar variaçōes na forma como os homens e as mulheres falam, diferenças de linguagem de uma geração para outra, de um grupo profissional para outro. É natural, também, que as pessoas que tiveram pouca ou nenhuma escolarização usem variedades do portugués diferentes daquelas usadas pelas pessoas que tëm acesso regular ao sistema de ensino. 
A única diferença que se pode estabelecer entre essas diferentes formas de falar é uma diferença de prestigio social e, nesse ponto, vamos perceber que o prestigio de uma variedade está diretamente relacionado com o prestígio de seus falantes dentro da organização social. As classes sociais desfavorecidas economicamente não gozam de nenhum prestígio dentro da sociedade. Conseqüentemente, a variedade lingüística usada pelas pessoas dessas classes não tem, também, prestígio algum. A diferença estabelecida $\dot{e}$, portanto, apenas uma diferença de valoração social e isso dá margem a muitos preconceitos reforçando a separação social existente. 0 mais grave é que esse preconceito toma proporções sérias quando, além de classificar essa fala como "errada", associa a forma de falar à capacidade intelectual do falante. Assim, acredita-se que as pessoas que falam "errado" são ignorantes, ou seja, desprovidas de capacidade de raciocínio. À medida que começamos a ver essa forma de falar apenas como uma das variedades da língua portuguesa, o preconceito dá lugar ao respeito pelos nossos semelhantes e desperta o interesse em observar as peculiaridades lingüisticas de cada tempo, de cada região, de cada grupo social, de cada falante.

\section{A LÍNGUA-PADRÃo}

Enquanto a escola serviu apenas às classes favorecidas, o problema da variação não era discutido, já que só recebia alunos que dominavam a variedade lingüística cultivada por ela. A partir do momento $\mathrm{em}$ que as classes populares começam a fazer parte dela, surgem problemas e a escola mostra-se impotente frente ao conflito que se estabelece.

É nesse ponto que a linguística, mais especificamente a sociolingüística, pode dar uma grande contribuição ao ensino, mostrando que não hả um único português, mas que há variedades lingüísticas. Cada um entra na escola trazendo o dialeto próprio da classe social em que está inserido, além de ser o dialeto próprio de sua região e da época $\mathrm{cm}$ que vive. 0 da escola é o dialeto das classes dominantes, por isso mesmo padrão.

Além da discriminação social, a escola tem, como resultado direto, a ineficiência do tipo de ensino que emprega, reduzindo a aprendizagem da língua à imposição de um padrão normativo de correção.

É importante deixar claro, no entanto, que a principal tarefa do professor de português é oportunizar aos seus alunos o dominio da linguapadrão sem que isso signifique a depreciaçāo das outras formas lingüísticas. 
Uma questão pertinente que se coloca com relaçāo a esse assunto é: se todas as variedades são boas, são corretas, por que ensinar a variedade-padrão? Vamos, nesse caso, encontrar diferentes respostas.

Alguns autores vêem a norma culta - outra designação para a línguapadrão - como uma forma de dominação social e de opressão cultural e por isso mesmo são contra o seu ensino. Outros defendem a necessidade de ensinar o dialeto-padrão para que o indivíduo possa adaptar-se à sociedade. Outros, ainda, enfatizam a necessidade de aquisiçāo da norma culta não como um instrumento que possibilita a adaptação, mas como uma arma contra a discriminação social, ou ainda, um instrumento que permite ao individuo a participação politica e, dessa forma, a possibilidade de lutar contra a estrutura social. Sem dúvida nenhuma, a norma culta é um instrumento de ascensão social e não prover o aluno de seu domínio é uma irresponsabilidade.

Justificamos, assim, a necessidade do ensino da língua-padrão desde que ela seja colocada, lingüisticamente, como uma variedade igual às outras mas que desfruta de um prestígio social diferente. Essa diferenciação valoriza algumas variedades em detrimento de outras e nasce não da diferença desta ou daquela forma em si, mas da importancia social que certas formas lingüisticas adquirem nas sociedades.

A concepção monolitica de língua com que a escola sempre trabalhou foi herdada de uma tradição gramatical comum a toda a civilização ocidental, que remota aos filólogos gregos do 11 século a.C. Reunidos na famosa Biblioteca de Alexandria - então uma cidade grega no delta do rio Nilo esses filólogos se aperceberam de que o grego falado à sua época era distinto daquele em que vinham vasados os pocmas homéricos, compostos cinco séculos antes. Como não tivessem ainda consciência de que a língua muda ao longo dos tempos, interpretaram a divergência como resultado de um processo de deturpação lingüistica causada pela ignorảncia do povo. A variedade contemporīnea foi entendida como uma forma degenerada da verdadeira língua grega, que tinha ficado num passado glorioso e encerrado.

0 equivoco alexandrino tornou foros de verdade indiscutivel e desde então a escola concebe a lingua dos autores clássicos como a forma verdadeira e exclusiva do idioma, banindo todas as demais variedades. Por intermédio dos gramáticos, a escola seleciona o que considera o melhor repertório de hábitos lingüisticos, que costuma buscar na literatura de séculos passados. Em consequiencia desse procedimento, passa-se a ter duas normas: uma norma culta real - aquela efetivamente praticada pelas classes 
cultas - e uma norma exclusivamente escolar, também chamada norma prescritiva, que, sem ser inteiramente artificial, é arcaizante.

No caso do Brasil, a norma escolar ainda soma o defeito de sua subserviência à norma prescritiva portuguesa. É por essa espécie de colonialismo normativo auto-imposto que se explica a razão de até hoje se preconizar a colocação dos pronomes pessoais átonos ao estilo português, em completa desconformidade com o que a elite brasileira pratica mesmo nas situações mais formais.

Como podemos ver, esse padrāo não se estabelece por acaso. Em todas as sociedades modernas, ele é fruto de um processo histórico seletivo sempre ligado aos grupos sociais dominantes. Portanto, mesmo quando o falante não domina as formas lingüísticas consideradas "corretas", ele luta por identificar-se com elas, porque sabe que, se não usá-las em certas situações, vai sofrer discriminação, censura e mesmo bloqueio à ascensão social.

Se por um lado a existência e as vantagens da língua-padrão são inegáveis, por outro lado é muito difícil descrevê-la rigorosamente ou dizer onde vamos encontrá-la. As gramáticas tradicionais, como já se viu, baseiam-se normalmente em exemplos de textos literários de autores clássicos, que, muitas vezes, estão muito distantes do padrão real do português do Brasil. Devemos lembrar que a literatura é um gênero especifico, com características próprias e não um instrumento que serve para qualquer finalidade. É importante observar que não há mais relação direta entre literatura e língua-padrão, pois o artista é livre para incorporar e criar as mais diferentes formas. Com certeza, hoje não podemos falar em línguapadrão sem levar em consideração, de algum modo, os meios de comunicação social (jornais e revistas, principalmente), em geral ignorados pelos manuais escolares, embora representem, de fato, o padrão brasileiro.

Apesar de toda essa controvérsia, podemos sistematizar alguns aspectos que devem ser levados em conta quando falamos de língua-padrão. A primeira questão a ser encarada é que a língua-padrão nāo é uniforme. Ela admite variações em diferentes sentidos. Podemos perceber claramente, por exemplo, a diferença de pronúncia, de vocabulário e de sintaxe de uma região para outra, o que comprova que a norma culta é marcada regionalmente. Notamos, ainda, que o mesmo falante empregará formas diferentes, todas aceitas como padrão, de acordo com o nível de formalidade que a situação exige. Além disso, cada falante tem seu estilo próprio, dando preferência a algumas formas em detrimento de outras $e$, assim, apresenta a 
língua-padrão com suas diferenças estilísticas. E, finalmente ninguém escreve como fala, o que nos leva à conclusão de que há um padrão escrito de um lado e um padrão oral de outro.

A outra questão a ser levada em conta é que a língua-padrão muda no tempo, apesar de que as formas lingüisticas consideradas padrão, principalmente na escrita, são mais resistentes à mudança. Podemos comprovar isso lembrando a regência de alguns verbos, a colocacão dos pronomes no português brasileiro ou o fenômeno da concordancia verbal nos casos em que o sujeito aparece depois do verbo. A língua oral, mesmo das faixas mais escolarizadas da população, demonstra nítidas evidências de mudança em relação aos itens gramaticais citados, mas essas transformações não chegaram ao padrão escrito de prestigio, embora sejam freqüentes em textos escolares e, dependendo do caso, até em textos de boa qualidade, escritos por bons escritores $\mathbf{e}$ jornalistas.

Por fim, é importante enfatizar que o domínio da língua-padrão nāo representa simplesmente o domínio de regras gramaticais.Esse domínio é apenas o ponto de partida do que é efetivamente importante: o texto. No entanto, a escola insiste no engano de crer que, ensinando conteúdos gramaticais, estå transmitindo a norma, ainda que a prescritiva. Assim conduzido o ensino de Português, não é de surpreender que redunde $\mathrm{em}$ fracasso, com danos para cada um dos alunos e para a sociedade em geral. 0 aparelho pedagógico, defrontado com esse malogro, não hesitou em providenciar acobertamento ideológico de sua inépcia: providenciaram-se, rapidamente, discursos de absolvição da escola e de condenação do aluno.

\section{O TRABALHO COM A VARIAÇÃO EM SALA DE AULA}

Toda a questão teórica levantada anteriormente é fundamental como ponto de partida para um trabalho eficiente em sala de aula. O objetivo central do ensino de língua portuguesa é levar os alunos ao domínio da língua-padrão nas suas modalidades oral e escrita. Portanto, o professor não vai ensinar as diferentes variedades existentes na língua, mas vai partir da variedade utilizada pelo grupo com que trabalha e, através de diferentes atividades, vai conduzi-lo ao domínio da norma culta. Para isso, o professor precisa dessa fundamentacão teórica e de um espirito de observação eficiente. 
E importante apresentar gradativamente a questão, ou seja, discutir com os alunos que a língua varia nas mais diferentes situações. Após essa apresentação, o professor deverá colocar a questão da língua-padrão, a questão do prestígio social (que não é só o modo como as classes dominantes falam que tem prestígio, mas também o seu modo de se comportar, o seu modo de se vestir, etc.), a importância e a utilidade do domínio desse padrão na vida de cada um.

Dizemos gradativamente porque apesar de as crianças desde muito cedo serem sensíveis a diferenças lingüísticas, elas não lhes atribuem significado social. É que a sensibilidade sociolingüistica só passa a desenvolver-se em torno do início da puberdade. Portanto, só de alunos de mais de dez anos tem sentido exigir a capacidade de discriminar os contextos em que se impõe a norma culta.

Por ser a escola uma das agências de socialização em potencial, ela exerce papel preponderante, imprescindível mesmo, no sentido de oferecer às classes desfavorecidas um instrumento lingüistico adequado para as inúmeras situações que se lhes oferecem. Nesse sentido, o domínio da variação estilítica e social seriam os eixos das atividades.

Para levar adiante essa proposta, é de importância vital que a escola evite incorrer no erro preconceituoso de que a capacidade do educando está relacionada com a sua classe sócio-econômica ou seja, ele fala assim porque é ignorante, porque não sabe pensar, etc. 0 estigma que a escola lança sobre as variedades rurais e populares é não só improdutivo como até nocivo à própria segurança lingüística do aluno, que se sentirá humilhado e, quem sabe o mais grave, dividido entre a lealdade cultural devida a seu grupo familiar e as valores de prestígio veiculados pela escola.

Assim, duas atitudes fundamentais devem ser tomadas: a primeira é que o professor elimine de seu vocabulário a dicotomia correto/incorreto, substituindo-a por formal/informal; a segunda é o respeito à variedade lingüística que seus alunos trazem de casa.

Para trabalhar a dicotomia formal/informal na língua oral, o professor precisa colocar diferentes situações e mostrar a alteração que isso vai acarretar na forma de cada um se expressar. Essa atividade poderá ser feita através da dramatização de um mesmo ato de comunicação em diferentes circunstâncias.

Como exemplo, poderiamos tomar o assunto FUTEBOL, e propor que cada um fale de seu time ou de um jogo assistido anteriormente, levando em conta as diferentes situações: 
- o assunto tratado por um grupo de amigos durante o recreio;

- debate sobre a mesmo assunto num programa de televisão;

- divulgação do mesmo assunto pelo comentarista responsável no jornal da televisão em horário nobre;

Conforme a situação vai mudando, o falante obrigatoriamente precisa mudar a sua maneira de falar, caminhando do informal para o formal e é deste último que o professor se servirá para introduzir as estruturas da língua-padrão.

Outra cena interessante a ser dramatizada é o pedido de emprego. Conforme o lugar a que a pessoa se habilita, ela, automaticamente, deve mudar a variedade de língua utilizada. Por exemplo:

- pedir enprego de servente de obras em uma construção civil;

- pedir emprego de cozinheiro(a) em um restaurante;

- pedir emprego de gargom em um restaurante;

- pedir emprego de garçom no restaurante de um hotel de luxo;

- pedir emprego em um banco;

- pedir emprego de secretário(a) em uma multinacional, e assim por diante.

Dessa forma estariamos trabalhando a lingua oral de forma mais realista, com objetivos determinados, fugindo daquelas atividades estéreis de apresentações de um assunto para a própria turma, que o professor, por não determinar as condiçōes de produçāo, não tem condiçōes ou não vê motivos para interferir na forma utilizada para se expressar.

A mesma metodologia deve se aplicada no momento da produção escrita. 0 texto escrito deve ser encarado, acima de tudo, como uma ponte entre dois ou mais interlocutores e, por isso, marcado pelas intenções de quem escreve, pelas características do assunto que reflete e pelo universo daquele a quem se dirige.

Portanto, as estratégias adotadas para a prática de texto, tanto oral como escrito, devem ser repensadas na escola. 0 aluno que tem como único interlocutor o professor, jamais poderá avaliar os diferentes registros da língua. Ao contrário, ele estará simplesmente incorporando um discurso escolar vazio e estéril.

Para mostrar os diferentes registros, o professor tem que, necessariamente, determinar a finalidade e o interlocutor do texto. Por exemplo, se pedimos ao aluno para escrever um bilhete ou uma carta ao colega comentando uma determinada situação, temos que aceitar o emprego de gírias, de formas reduzidas como pra, tá, tô. No entanto, se o bilhete ou a carta é para 
o diretor da escola ou para o prefeito da cidade, essas formas não poderão ocorrer. Assim, a escola começa a trabalhar com uma linguagem mais viva e, passo a passo, dará condições para que o aluno adquira as formas de mais prestígio.

Dessa forma, estamos convencidos de que poderemos alterar um pouco os resultados do ensino de língua portuguesa e reverter o quadro lamentável descrito por Gustavo Bernardo que vem citado a seguir:

Aprendemos a falar na vida. Assim como a calar. Quem cala, não consente. Quem cala, ou está se guardando ou se submetendo. Entretanto, existem variaçōes barulhentas da submissão calada,onde o que se fala é o nada. Uma destas variaçōes parece ser a rodação escolar'.

Redaçăo inquieta, p. 3-6.

\section{RESUMO}

Este trabalho abonda as dificuldades $\mathrm{cm}$ matéria de lingua que a escola passou a enfrent ar com a súbita ampliação de sua clientela, no processo de democratização do ensino. A diversidade lingüistica não encontrou uma resposta adequada e estabeleceu um conflito,que se busca analisar à luz da sociolingüistica.

\section{REFERÊNCIAS BIBLIOGRÁFICAS}

CAMACHO, Roberto G. A variação lingüistica. In: SÃO PAULO -SECRETARIA DE ESTADO DA EDUCAÇÃO. Subsídios à proposta curricular de língua portuguesa para o $1^{\circ}$ $e 2^{\circ}$ graus, São Paulo, 1988. v.I.

FARACO, C. A.; MANDRIK, D. Prática de redaçāo para alunos universitários. Petrópolis: Vozes, 1987.

FARACO, C. A.,; TEZZA, C. Prálica de texto - língua portuguesa para nossos estudantes. Petrópolis; Vozes, 1992.

GERALDI, J. W. Concepções de linguagem e ensino de português. In: GERALDI, j. W. (org.) O texto na sala de aula. Cascavcl; Assoeste, 1984.

SOARES, Magda. Linguagem a escola - uma perspectiva social. S. Paulo; Ática, 1986.

TARALLO, Femando. A pesquisa sociolingüística. S.Paulo: Ática, 1985. 